\title{
Hepatoprotection of Lycii Fructus Polysaccharide against Oxidative Stress in Hepatocytes and Larval Zebrafish
}

\author{
Fang Zhang $\mathbb{D}^{1}{ }^{1}$ Xia Zhang $\mathbb{D}^{2,3}$ Yutian Gu ${ }^{1},{ }^{1,4}$ Min Wang ${ }^{\circ},{ }^{5}$ Sheng Guo, ${ }^{1}$ \\ Jiazheng Liu $\mathbb{D}^{1}$, ${ }^{1,6}$ Xiaofei Zhang $\mathbb{D}^{1},{ }^{1}$ Zihan Zhao $\mathbb{D}^{1},{ }^{1}$ Bowen Qian $\mathbb{D}^{1},{ }^{1}$ Yichao Yan $\mathbb{D}$, ${ }^{1}$ \\ Li Yu $\mathbb{D},{ }^{1}$ Chunlei Xu $\mathbb{D},{ }^{1}$ Chunmei Liu, ${ }^{1}$ Funing Cao, ${ }^{7}$ Dawei Qian $\mathbb{D}^{1},{ }^{1}$ and Jin-ao Duan $\mathbb{D}^{1}$ \\ ${ }^{1}$ Jiangsu Collaborative Innovation Center of Chinese Medicinal Resources Industrialization, School of Pharmacy, Nanjing University \\ of Chinese Medicine, Nanjing 210023, China \\ ${ }^{2}$ School of Pharmacy, Ningxia Medical University, Yinchuan 750004, China \\ ${ }^{3}$ Key Laboratory of Hui Ethnic Medicine Modernization of Ministry of Education, Yinchuan 750004, China \\ ${ }^{4}$ Hong Kong Polytechnic University, Hong Kong 999077, China \\ ${ }^{5}$ School of Medicine, Nanjing University of Chinese Medicine, Nanjing 210023, China \\ ${ }^{6}$ State Key Laboratory of Quality Research in Chinese Medicine, Macau Institute for Applied Research in Medicine and Health, \\ Macau University of Science and Technology, Macau 999078, China \\ ${ }^{7}$ Jiangsu Golden Thinking Software Co., Ltd., Nanjing 210042, China
}

Correspondence should be addressed to Jin-ao Duan; dja@njucm.edu.cn

Received 23 June 2020; Revised 28 January 2021; Accepted 2 February 2021; Published 18 February 2021

Academic Editor: Jayeeta Ghose

Copyright (C) 2021 Fang Zhang et al. This is an open access article distributed under the Creative Commons Attribution License, which permits unrestricted use, distribution, and reproduction in any medium, provided the original work is properly cited.

\begin{abstract}
Scavenging of oxidative stress by antioxidants may provide a therapeutic strategy for nonalcoholic fatty liver disease (NAFLD). Increasing evidence is supporting the potential application of natural resourced polysaccharides as promising prevention or treatment strategies against NAFLD. In the current study, an acidic heteropolysaccharide, LFP-a1, was isolated and purified from Lycii fructus with successively hot water refluxing extraction, alcohol precipitation, protein removal, and DEAE-52 cellulose chromatographic separation. LFP-a1 was a complicated structured polysaccharide with an average MW of $4.74 \times 104$ $\mathrm{Da}$ and composed of 6 monosaccharides and 1 uronic acid. Preexposure of LFP-al could increase the cell viability and reverse the abnormal oxidative stress though inhibition of mitochondrial-mediated apoptotic pathway and correction of cell cycle progression against $\mathrm{H}_{2} \mathrm{O}_{2}$ hepatoxicity in NAFLD model L02 cells. Consistently, in vivo study in thioacetamide- (TAA-) induced NAFLD model zebrafish larvae showed LFP-al preserved the liver integrity and alleviated TAA-induced oxidative stress through downregulation of abnormal apoptosis. These observations indicated the hepatoprotective activity of LFP-al, which may be applied for the prevention or treatment of NAFLD or other oxidative stress-related diseases.
\end{abstract}

\section{Introduction}

The conception of oxidative stress basically defines a disturbed condition in which accumulative molecular and/or cellular oxidative injury is observed with the disequilibrium of reactive oxygen species (ROS) generation and in-build antioxidant defensing system [1]. Excessive, repetitive, and/or sustained oxidative stress stems from elevated formation and accumulation of reactive oxygen intermediates (ROI, including free radicals, hydrogen peroxide, hydroxyl radicals, and superoxide anion) have been implicated to be closely interconnected with the initiation and progression of a myriad of pathological lesions which often result in metabolic damage such as aging, cardiovascular diseases, neurological disorders, inflammation, and liver disease. ROS accumulation in hepatocyte is regarded as a substantial contributor in the pathogenesis of a hepatic manifestation of metabolic syndrome, nonalcoholic fatty liver disease (NAFLD), ranging from steatosis, steatohepatitis, and cirrhosis to carcinoma [2]. Oxidative stress-mediated toxicity, 
accompanied by changes in lipid metabolism, gradually destroys the balance between ROS production and detoxification pathways, which further results in feedback overaccumulation of ROS, deficiencies of antioxidant defense, and inevitable impairment of mitochondrial respiratory function in hepatocyte. The excessive and sustained oxidative stress contributes to hepatocellular damage that leads to functional impairments. Considering the constant exposure of liver cells to oxidative stress, scavenging of ROS by antioxidants may provide a persuasive therapeutic strategy targeting at least one key pathological event related to NAFLD, i.e., solemn oxidative damage [3]. Actually, previous research has established the protective or therapeutic potency of natural antioxidants upon oxidative injury induced by nonalcoholic insult [4].

One of the scientific hallmarks of the past decades has been the technologies and methodologies to identify the details of structure of polysaccharides, which accelerate the pace of discovery of polysaccharide functions [5]. The current accomplishments have led to the establishment of polysaccharide-related studies as one of the fundamental areas of biological and biochemical studies, as exemplified by the increasingly recognized spectrum of pharmacological benefits, such as ant-oxidic, antiaging, antimicrobial, anticancer, antithrombotic, hypoglycemic, immunomodulatory, and gut microbial modulatory [6-11]. Emerging innovative research output has evaluated applying natural resourced polysaccharides as promising prevention or treatment strategies against a variety of human disease models $[12,13]$. Specially, unlike the currently used synthetic chemical components which were suspected to be associated with hepatic damage resulted from the treatment, natural polysaccharides have been supported by interdisciplinary research to be effective with innate low toxicity and natural compatibility. Applying natural polysaccharides as promising protective agent is a rising concern to protect against chemical-induced hepatic injury.

Lycii fructus, also called goji berry or wolfberry, is the bright reddish orange fruit of solanaceous shrubbery Lycium barbarum L. Lycii fructus has long been worldwide consumed as functional dietary tonic in the recipes of worldwide regimen based on the recorded "liver nourishing, lung moistening, and eye lubricating" efficacies in ancient script. In the late years, motivated by the expectations for the promotion of health and longevity, Lycii fructus has been increasingly popular due to its recognized diverse nutritive, preventive, and therapeutic properties including immunoregulation, antioxidation, antiaging, cryoprotection, hepatoprotection, and cancer prevention [14].

Lycii fructus is a rich resource of complex mixture of reported antioxidants, among which are some bioactive small molecules like vitamin C, carotenoids, and polyphenols, which may act in concert to exert activities [15]. Apart from the identified small chemical constituents, Lycii fructus polysaccharides (LFPs) are highlighted by increasing interest to be responsible for its antioxidative capacity, implying that LFPs may be a potential protective or therapeutic agent against liver damage [16]. Therefore, in the present study, we purified LFP fractions from Lycii fructus. In addition, in vitro and in vivo assays were performed upon human hepatocyte cell line L02 and zebrafish larvae to further our understanding of the latent potentialities and the underlying mechanisms of LFP utilization in protecting liver against oxidative stress in NAFLD.

\section{Materials and Methods}

2.1. Chemicals and Materials. The dried fruits of Lycii fructus were purchased from Bairuiyuan Gouqi Corp. (Yinchuan, Ningxia Autonomous Region, P.R. China) and identified by the corresponding author based on the morphological and histological features according to the standards of Chinese Pharmacopoeia (2015 version). Voucher specimen was deposited in Jiangsu Collaborative Innovation Center of Chinese Medicinal Resources Industrialization. DEAE-52 cellulose was purchased from Whatman Ltd. (Kent, UK). Dulbecco's modified Eagle's medium (DMEM) and fetal bovine serum (FBS) were purchased from Life Technologies (Grand Island, NY, USA). Propidium iodide (PI) and Hoechst 33342 were purchased from Sigma-Aldrich (St. Louis, MO, USA). Cell counting kit-8 (CCK-8) and 5-Ethynyl-2'-deoxyuridine (EdU) Imaging Detection Kit were purchased from KeyGEN Biotech Int. (Nanjing, China). Annexin V/fluorescein isothiocyanate (FITC)-PI apoptosis detection kits were purchased from BD Biosciences (Franklin Lakes, NJ, USA). Trizol reagent and reverse transcriptase kits were purchased from Takara Biomecicals Co., Ltd. (Dalian, China). All other chemicals and regents used were of the commercially highest grade unless specifically noted.

2.2. Polysaccharide Extraction and Purification from Lycii Fructus. The acidic polysaccharide LFP-al was extracted and purified from Lycii fructus with hot water extraction and subsequently purification with ion-exchange chromatography. Briefly, ground Lycii fructus were fluxed with $80 \%$ ethanol at $75^{\circ} \mathrm{C}$ for $2 \mathrm{~h}$ followed by acetone-petroleum ether at $55^{\circ} \mathrm{C}$ for $1 \mathrm{~h}$ to remove small lipophilic molecules and pigment. The residue was subjected to two times of reflux water extraction at $90^{\circ} \mathrm{C}$ for $2 \mathrm{~h}$ each time. The polysaccharides were precipitated with ethanol and deproteinated with Sevag reagent (chloroform : butyl alcohol $4: 1$ ) to give deproteinized LFPs. LFPs were further fractionated on an ion-exchange DEAE-52 cellulose column. After the neutral fractions were removed by water washing, the acidic fraction was eluted with $0.25 \mathrm{M}$ aqueous $\mathrm{NaCl}$ and collected based on the chromatography profile at $490 \mathrm{~nm}$ determined by phenolsulfuric acid assay. The collected fraction was concentrated, dialyzed, and freeze dried given a purified fraction LFP-a1, which was subjected to further structural elucidation and activity evaluation.

\subsection{Primary Structure and Microstructure Characterization of LFP-a1}

2.3.1. General Analysis. Carbohydrate content and protein content were measured by phenol-sulfuric acid method and Bradford method using galactose and bovine serum albumin as standard, respectively $[17,18]$. Congo red test was used to detect the presence of triple-helical conformation [19]. 
2.3.2. FT-IR Spectroscopy. LFP-a1 sample was subjected to a Thermo Nicolet iS5 IR spectrometer (Thermo Scientific, USA) to record FT-IR spectrum within the range of 4000$400 \mathrm{~cm}^{-1}$ to investigate the vibrations of molecules and polar bonds between the different atoms.

2.3.3. Molecular Weight Distribution of LFP-a1. High performance gel permeation chromatography (HPGPC) was used to visualize the homogeneity and MW distribution on an ELEOS System (Wyatt Technology Co., Santa Barbara, CA, USA) equipped with RID-10A refractive index detector and an OHpak SB-802.5HQ column $(8 \mathrm{~mm} \times 300 \mathrm{~mm}$, Showa Denko Co., Tokyo, Japan). Sample was resolved in $0.1 \mathrm{M}$ NaNO3 and eluted at a flow rate of $0.5 \mathrm{~mL} / \mathrm{min}$. MW distribution was calculated with reference to the standard curve prepared with T-series Dextran.

2.3.4. Monosaccharide and Uronic Acid Composition Assays of LFP-a1. GC-MS-based monosaccharide and uronic acid composition assays were performed after LFP-al sample was hydrolyzed in $2 \mathrm{~mL}$ of $2 \mathrm{M}$ TFA at $110^{\circ} \mathrm{C}$ for $2 \mathrm{~h}$ and derived into alditol acetates or $\mathrm{N}$-propylaldonamlde acetates according to the method of Lehrfeld [20] and loaded on an Agilient 7000C GC/MS Triple Quard system (Agilent Technologies, Santa Clara, CA, USA) equipped with an Agilent HP5-ms capillary column $(30 \mathrm{~m} \times 0.25 \mathrm{~mm} \times 0.25 \mu \mathrm{m})$. Oven temperature was programmed as follows: $100^{\circ} \mathrm{C}$ for $3 \mathrm{~min}$, then to $200^{\circ} \mathrm{C}$ at $20^{\circ} \mathrm{C} / \mathrm{min}$ and $200^{\circ} \mathrm{C}$ for $2 \mathrm{~min}$, to $230^{\circ} \mathrm{C}$ at $5^{\circ} \mathrm{C} / \mathrm{min}$ and $230^{\circ} \mathrm{C}$ for $2 \mathrm{~min} ; 280^{\circ} \mathrm{C}$ at $10^{\circ} \mathrm{C} / \mathrm{min}$ $280^{\circ} \mathrm{C}$ for $8 \mathrm{~min}$. Data was analyzed with Agilent MassHunter Workstation.

\subsection{Hepatoprotection of LFP-a1 In Vitro}

2.4.1. Cell Line and Maintenance. The human hepatocyte cell line L02 was purchased from Shanghai Cell Bank of Chinese Academy of Science (Shanghai, China). Cells were maintained as mycoplasma-free subconfluent monolayer cultures in DMEM supplemented with $10 \%$ inactivated $\mathrm{FBS}$ at $37^{\circ} \mathrm{C}$ in a humidified $5 \% \mathrm{CO}_{2}$ incubator. In order to evaluate the cytoprotective effects of LFP-a1 in a model of oxidative stress in cultured cells, the following indices were measured: (1) cell viability (CCK8) and cell proliferation (EdU assay), (2) indices of cellular oxidative stress and antioxidant markers, (3) cell apoptosis, and (4) cell cycle distribution.

2.4.2. Cell Viability Assay and Cell Proliferation Assay. L02 cells were seeded at a density of $1 \times 104$ cells $/ \mathrm{cm}^{2}$ in triplicate in 96-well plates and allowed to attach before treatment. Cells were them exposed to a series of concentrations of LFP-a1 $(0.5,1,2 \mathrm{mg} / \mathrm{mL})$ for $24 \mathrm{~h}$ and $\mathrm{H}_{2} \mathrm{O}_{2}(40,70,100 \mu \mathrm{M})$ for $24 \mathrm{~h}$ separately or successively. Cell viability was then determined with CCK8 assay that shows the mitochondrial activity of living cells with the assistance of microplate spectrophotometer (Infinite 200 PRO, TECAN Inc. Switzer). Cell viability index was expressed as percentage of vehicle control (cells only suffered medium change) normalized to $100 \%$. In addition, cell proliferation was evaluated with cells seeded in 6-well plates by EdU imaging detection. Briefly, cells were treated as described above, then $10 \mu \mathrm{M}$ EdU was added for $2 \mathrm{~h}$ before the end of the culture to label proliferating cells. After being fixed by $4 \%$ paraformaldehyde and added by Click-iT reaction cocktail, cells were subjected to Hoechst 33342 for nuclei counterstaining. Cell proliferation, expressed as percentage of EdU positive cells to all cells, was achieved by the EdU- and Hoechst 33342-stained cells in the overlay photographs of five random visual fields in each well under a fluorescent microsystem (Leica DMI3000B, Wetzlar, Germany) facilitated with LAS program. Quantification was performed with image J software (https://imagej.nih.gov/ij/).

2.4.3. Biochemical Determination of Hepatic Oxidative Stress and Antioxidant Indicators. L02 cells seeded in 96-well plates were cultured and pretreated with LFP-A1 for $24 \mathrm{~h}$, after which cells were challenged with $70 \mu \mathrm{M}$ of $\mathrm{H}_{2} \mathrm{O}_{2}$ for another $24 \mathrm{~h}$ as described in Section 2.4.2. Intracellular ROS and oxidative stress (NO, MDA levels as oxidative damage markers, activities of SOD, GSH-Px, and CAT, GSH level, and T-AOC as antioxidant markers) were assessed with commercially available assay kits (Jiancheng Bioengineering Int. Nanjing, China) by strictly following the manufacturer's instructions (Abbreviations: NO, nitric oxide; MDA, malondialchehyche; SOD, superoxide dismutase; GSH-Px, glutathione peroxidase; CAT, catalase; GSH, reduced glutathione, T-AOC, total antioxidant capacity).

2.4.4. Cell Apoptosis Analysis. Apoptosis was first detected with fluorescent Hoechst 33342-assisted nuclear staining. Briefly, cells were cultured and treated as described in Section 2.4.3, then washed and incubated with $10 \mu \mathrm{g} / \mathrm{mL}$ of Hoechst 33342 for $20 \mathrm{~min}$ at $37^{\circ} \mathrm{C}$ in dark. Apoptosis was observed by photographing the cells of five random visual fields in each well.

Apoptosis was further quantitatively detected with Annexin V-FITC/PI double staining in conjunction with flow cytometry. L02 cells were seeded and cultured in $25 \mathrm{ml}$ flasks and treated as described in Section 2.4.3. Cells were then washed, harvested, resuspended, and double-stained with $2.5 \mathrm{mg} / \mathrm{ml}$ Annexin V-FITC for $15 \mathrm{~min}$ and $1 \mathrm{mg} / \mathrm{ml}$ PI for $10 \mathrm{~min}$ in dark. DNA histograms were obtained by fluorescence activated cell sorting analysis (FAQS) on a BD AccuriC6 Cytometer (BD Biosciences, Franklin Lakes, NJ, USA) affiliated with BD FACSuite Flow Cytometry software. For each analysis, at least 10,000 gated events were collected. Percentage of Annexin V-positive cells gated in the PI-negative/positive fractions was calculated as the percentage of cells in early/late apoptosis, respectively.

2.4.5. Western Blot Analysis. Proteins were extracted from cell pellets in ice-cold lysis buffer. After protein concentrations determined, equal amounts of total protein $(30 \mu \mathrm{g})$ of each sample were fractionated on $10 \%$ SDS-PAGE gel, electro-transferred onto $0.2 \mu \mathrm{m}$ nitrocellulose membrane, and immune-blotted with diluted corresponding primary antibodies overnight at $4^{\circ} \mathrm{C}$ followed by horseradish peroxidase-conjugated secondary antibodies for 1 hour at $25^{\circ} \mathrm{C}$. Chemiluminescence signal was visualized and recorded with the ChemiDoc ${ }^{\mathrm{TM}}$ Touch Imaging System (Bio-Rad Laboratories, Inc., USA). 
2.4.6. Cell Cycle Distribution Analysis. Cell cycle distribution analysis was performed using flow cytometry on the same BD AccuriC6 Cytometer. After the corresponding treatment period of LFP-al and $\mathrm{H}_{2} \mathrm{O}_{2}$ as described in Section 2.4.3, both adherent and detached cells were collected and fixed with ice cold 70\% ethanol overnight. Cells were resuspended in $1 \mathrm{~mL}$ staining solution (PBS containing $0.1 \%$ Triton X$100,10 \mu \mathrm{g} / \mathrm{mL}$ DNase-free RNase and $50 \mu \mathrm{g} / \mathrm{mL}$ PI) for 30 min in dark. At least 30,000 gated events were collected to permit each cell cycle analysis. Histograms were analyzed using Flow-Jo version 10.0 (Tree Star, Ashland, OR, USA).

\subsection{Hepatoprotection of LFP-a1 In Vivo}

2.5.1. Zebrafish Strains and Husbandry. Zebrafish experiment was approved by the Animal Care and Use Committee of Nanjing University of Chinese Medicine. Wild-type zebrafish (AB strain) and a transgenic line of zebrafish with enhanced liver-specific green fluorescent protein (eGFP) expression $[\operatorname{Tg}(l f a b p 10 a-e G F P)]$ were purchased from Xinjia Zebrafish Resource and Screening Platform (Nanjing, China). Adult zebrafish were kept in an automatic recirculating tank at a density of 1.5 fish per liter at the following conditions: $\mathrm{pH} 7.5-8.0$, dissolved oxygen $7.5 \mathrm{mg} / \mathrm{L} 28.5^{\circ} \mathrm{C}$, and constant $14 / 10 \mathrm{~h}$ light/dark cycle. Newly fertilized eggs were collected from natural spawning within $30 \mathrm{~min}$ and randomly sorted into 6-well culture plates containing embryo medium and kept in a $28.5^{\circ} \mathrm{C}$ incubator controlled in 14/10 h light/dark cycle.

2.5.2. Waterborne Exposure of Zebrafish to LFP-a1 and Thioacetamide (TAA). 3 dpf larvae in normal development were randomly allocated into five groups and transferred into 12-well plate (10 larvae in a well, 100 larvae for one group). Larvae were exposed to different concentrations of LFP-a1 $(0,0.2,0.5$, and $1 \mathrm{mg} / \mathrm{mL})$ for three days, followed by $7 \mathrm{mM}$ TAA insult for another $3 \mathrm{~d}$. Data were expressed as a percentage of vehicle control (larvae only suffered medium change) normalized to $100 \%$.

2.5.3. Fluorescence Image Acquisition. The liver green larvae after treatment were anesthetized with $0.16 \%(w / v)$ tricaine, mounted with 3\% methylcellulose, and imaged in bright and fluorescent field under a Leica stereo microsystem to observe the liver phenotype in a lateral view. The size and fluorescence intensity were obtained by Image J.

2.5.4. Transaminase Analysis. For the hepatic transaminase activity analysis, the $\mathrm{AB}$ strain larvae were collected, anesthetized, and homogenized in $400 \mu \mathrm{L}$ ice-cold saline. The homogenate was centrifuged at $15,000 \times \mathrm{g}$ for $15 \mathrm{~min}$ at $4^{\circ} \mathrm{C}$ to remove debris. The supernatant was then analyzed for alanine transaminase (ALT) and aspartate transaminase (AST) activities using the commercial spectrophotometric diagnostic kits (Jiancheng Bioengineering Int. Nanjing, China).

2.5.5. Whole-Mount Oil Red O Staining. Larvae after treatment were fixed in $4 \%$ paraformaldehyde at $4^{\circ} \mathrm{C}$ overnight and washed twice in phosphate-buffered saline containing $0.1 \%$ Tween-20, followed by $0.5 \%$ Oil Red O working solu- tion staining in dark for $30 \mathrm{~min}$. Samples were then rinsed in successive $80 \%, 40 \%$, and $20 \%$ propylene glycol to remove nonspecific staining. Images were obtained in bright field under a Leica stereo microsystem to observe the liver phenotype in a lateral view. The size and mean gray value were quantified by Image $J$ to quantitatively evaluate hepatocyte steatosis.

2.5.6. Oxidative Stress and Antioxidant Indicators Determination. To evaluate the protective effect of LFP-a1 against TAA-induced oxidative stress, the $\mathrm{AB}$ strain larvae were subjected to oxidative stress measure. Larvae were anesthetized and homogenized in $400 \mu \mathrm{L}$ ice-cold saline. The homogenate was centrifuged at $15,000 \times \mathrm{g}$ for $15 \mathrm{~min}$ at $4^{\circ} \mathrm{C}$ to remove debris. The supernatant was then subjected to determine the biomarker of oxidative stress as described in 2.4.3.

2.5.7. RNA Extraction and Real-Time Quantitative PCR ( $q P C R)$. Total RNA was isolated from larvae using TRIzol reagent. Approximately $1 \mu \mathrm{g}$ of RNA was reversetranscribed into cDNA using PrimeScript RT Master Mix. qPCR application was performed in a total volume of $20 \mu \mathrm{L}$ containing $10 \mu \mathrm{L}$ SYBR Green One-Step RT-PCR Master Mix and $1 \mu \mathrm{L}$ cDNA template on a real-time quantification system (LightCycler 96, Roche, Switzerland). Quantification was analyzed using the comparative $\mathrm{Ct}$ relative quantification method formula $2^{-\triangle \Delta C T}$, with housekeeping gene GADPH mRNA used as invariant control to normalize the mRNA of target genes. PCR applications were performed in triplicate. Specific primers summarized in Table S1 were used in this study.

2.6. Statistical Analysis. Data results were presented as mean \pm standard deviation (SD) of at least three independent experiments. Differences were considered statistically significant once $p$ values were less than 0.05 using one-way analysis of overall variance (ANOVA) followed by Tukey's multiple comparison tests. All statistical analyses were performed using GraphPad Prism software 8 project for Windows (GraphPad Software, San Diego, CA, USA).

\section{Results and Discussion}

3.1. Extraction, Purification, and Physicochemical Properties of LFP-a1. Water soluble deproteinized LFPs were successfully isolated from Lycii fructus powder by a series of procedures including ethanol infusion, water extraction, ethanol precipitation, and deproteination. After subsequent purification by DEAE-cellulose, an acidic polysaccharide LFP-al was finally achieved for further evaluation. After being lyophilized, LFP-al was fluffy and yellowish in color. The contents of total carbohydrate and protein of LFP-al were estimated to be $87.43 \%$ and $3.12 \%$, respectively. LFP-a1 was soluble in water and practically insoluble in acetone, ethanol, chloroform, diethyl ether, and ethyl acetate. LFP-al showed negative iodine-potassium iodide reactions, indicating the absence of starch type polysaccharide. No red shift of maximum absorption was observed at any concentrations in Congo red test, indicating that LFP-al did not form a 
triple-helical conformation in solution. Infrared spectroscopy ranged of $400-4000 \mathrm{~cm}^{-1}$ exhibited typical absorption peaks assigned to saccharide matrix as shown in Figure 1(a) and summarized in Table 1. Monitored by HPGPC, the MW distribution profile of LFP-al showed a dominated continuous peak accompanied with a minor component of higher $\mathrm{MW}$ and a lower $\mathrm{MW}$, indicating the polydisperse nature of LFP-al (Figure 1(b)). The weight-average MW of the dominated peak was $4.74 \times$ $104 \mathrm{Da}$ as calculated by the calibration curve. Meanwhile, LFP-a1 was composed of rhamnose, arabinose, xylose, mannose, glucose, galactose, and galacturonic acid in molar ratio of $8.87: 37.17: 0.61: 0.52: 6.84: 37.20: 8.79$, indicating a complicated composition of LFP-a1 (Figures 1(c) and 1(d)).

\subsection{Hepatoprotection of LFP-al on $\mathrm{H}_{2} \mathrm{O}_{2}$ - Insulted NAFLD Model L02 Cells In Vitro}

3.2.1. LFP-a1 Attenuated Cytotoxicity Induced by $\mathrm{H}_{2} \mathrm{O}_{2}$ in L02 Cells. As a strong chemical factor of oxidants, $\mathrm{H}_{2} \mathrm{O}_{2}$ can penetrate hepatic cell membrane easily into cell nucleus without being enzymatic degraded and trigger complex hepatic disorder caused by overdose ingestion of toxin. One of the pathological mechanisms has been demonstrated to be the involvement of oxidative stress. Nowadays, this $\mathrm{H}_{2} \mathrm{O}_{2}$-trigged cell model has been widely used as an in vitro cellular screening platform to investigate hepatotoxicity and hepatoprotection efficacy. Hereby, L02 cells were subjected to exogenous addition of LFP-al and/or $\mathrm{H}_{2} \mathrm{O}_{2}$ to address the potential cytoprotection of LFP-al against oxidative stress-induced hepatotoxicity. Colorimetric cck-8 assay and Edu imaging assay were performed to measure the mitochondrial metabolic rate of growing cells as an indirect value of cell viability and cell proliferation, respectively. Different concentrations of LFP-al (ranging from 0 to $2 \mathrm{mg} / \mathrm{mL}$ ) exposure induced negligible viability loss with respect to vehicle control L02 cells (data not shown). In sharp contrast, as depicted in Figure $2(\mathrm{a}), \mathrm{H}_{2} \mathrm{O}_{2}$ induced significant inhibition of cell survival in a dose-dependent manner. When cells were pretreated with LFP-a1 for $24 \mathrm{~h}$, however, cell viability was gradually restored to $61.6 \%$ at $0.5 \mathrm{mg} / \mathrm{mL}$ and $71.3 \%$ at $2 \mathrm{mg} / \mathrm{mL}$ of LFP-a1, respectively. Similarly, as shown in Figures 2(c) and 2(d), exposure of $\mathrm{H}_{2} \mathrm{O}_{2}$ seriously inhibited L02 proliferation. Pretreatment with LFP-a1 progressively increased the cell proliferation to $10.74 \%$ at $0.5 \mathrm{mg} / \mathrm{mL}$ and $23.81 \%$ at $2 \mathrm{mg} / \mathrm{mL}$ of LFP-1, respectively, as evidenced by the increased number of viable EdU-positive cells. This pattern of cell viability and cell proliferation ambiguously indicated that LFP-al had protective potentials by significantly attenuating $\mathrm{H}_{2} \mathrm{O}_{2}$-induced cytotoxicity in L02 cells.

3.2.2. LFP-al Mitigated $\mathrm{H}_{2} \mathrm{O}_{2}$-Induced Oxidative Stress Scenario. ROS generation during metabolism in normal physiological-steady state is compensated for by the endogenous antioxidant system. However, excess ROS accumulation can result in oxidative stress, which was believed to be one of the real culprits responsible for the progressive decline of cell health and for the consequent structural and functional alteration $[21,22]$. ROS production was consequently been con- sidered as a routine index of overall oxidative stress in living cells [23]. Uncharged NO concentration increased greatly upon reaction with superoxide radical, serving as an important intra- and intercellular messenger in oxidative stress [24]. Current therapeutic strategies for NAFLD majorly focused on the reduction of hepatic lipid overaccumulation. Based on the fact that lipid metabolism was closely related oxidative stress, MDA, one of the important end products of lipid peroxidation triggered by ROS, was identified to be a crucial biomarker reflecting oxidative damage to molecules [25]. In addition, SOD, GSH-Px, and CAT collectively constitute a line of a cellular antioxidant enzyme in the endogenous antioxidant defense system involved in ROS scavenging by converting superoxide and removing peroxide [26]. GSH, a tripeptide that works by interrupting free radical chain reactions [27], works as a nonenzymatic mechanism with the enzymes in a mutually supportive way to provide a protective defense against ROS. When the ROS increased to an extent beyond the capacity of the endogenous defense system, oxidative stress may be caused. The development and treatment of oxidative-stress was usually described by measurement of T-AOC, an indicative of the cellular ability to counteract oxidative stress-related damage.

Increasing lines of evidence proved that oxidant $\mathrm{H}_{2} \mathrm{O}_{2}$ induces acute NAFLD-like oxidative stress in different kinds of cells. This cell model has provided a useful instrument for clarifying the underlying mechanism and probing possible treatment for NAFLD in the fields of hepatology [28]. Investigating the effects of LFP-al upon oxidative stress in L02 cells could provide more direct evidence for its potential application. Therefore, the variation of intracellular ROS production and indices interpreting oxidative stress were tracked and measured to assess the protective activity of LFP-a1 against oxidative stress in $\mathrm{H}_{2} \mathrm{O}_{2}$-challenged L02 cells (Figure 3 ).

As illustrated in Figure 3, considerable overproduction of intracellular ROS, NO production, and MDA formation were observed in $\mathrm{H}_{2} \mathrm{O}_{2}$-challenged groups, accompanied by loss of both enzymatic (SOD, GSH-Px, and CAT activities) and nonenzymatic (GSH levels) mechanism, indicating disturbance in the normal physiological redox state of L02 cells under $\mathrm{H}_{2} \mathrm{O}_{2}$ insult. On top of this disturbance, these oxidative stress indices could be dose-dependently recovered with LFP-al pretreatment, as characterized by the alleviated intracellular ROS production, NO production, MDA generation, and renewed endogenous SOD activity, GSH-Px activity, CAT activity, and GSH level. Consistently, measurement of T-AOC provided similar scenario. The trend of changing observed was correlated with the suppression of intensified ROS-induced oxidative stress in L02 cells. These events collectively pointed to the suggestion that upstream LFP-a1 treatment was able to specifically reverse the abnormal state of ROS release, lipid peroxidation damage, and inner antioxidants activity, indicating that LFP-al had a wide scope to sequester ROS involved to prevent oxidative stress. Inhibition of ROS production could be one of the mechanisms for the cytoprotection of $\mathrm{H}_{2} \mathrm{O}_{2}$ challenged L02 cells. 


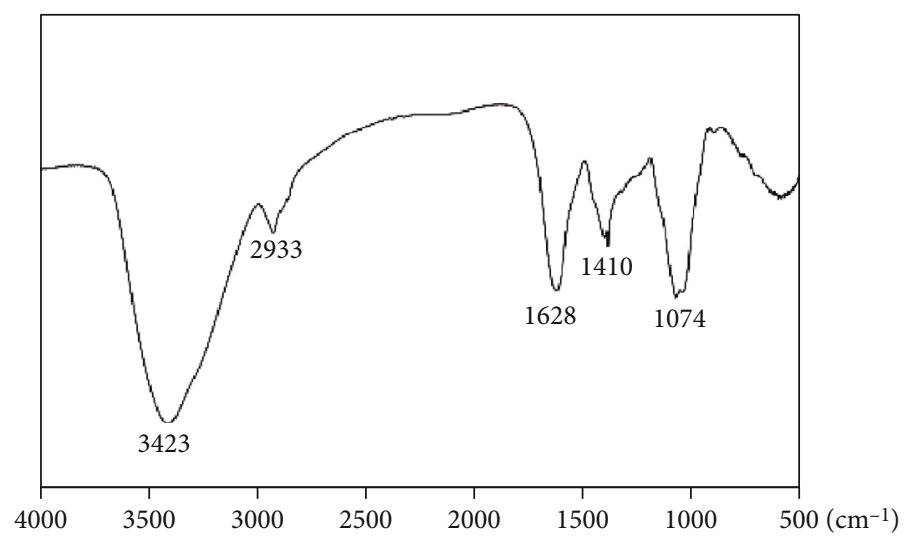

(a)

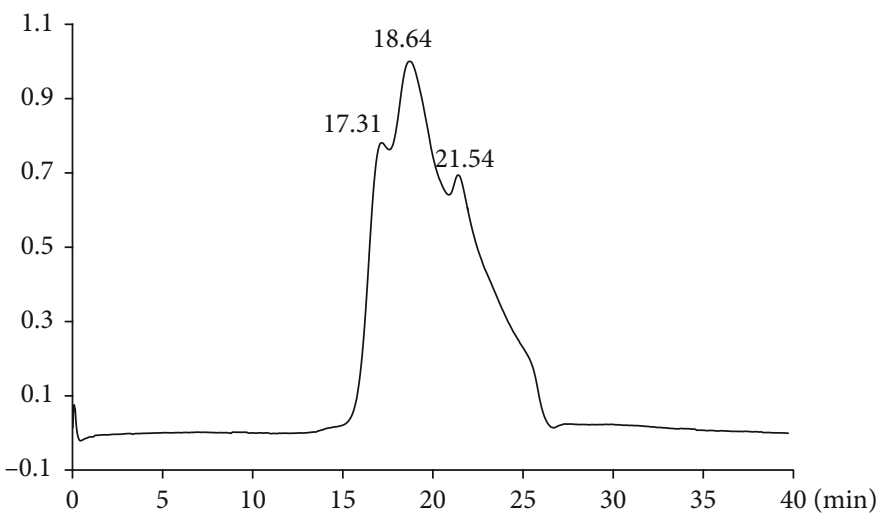

(b)

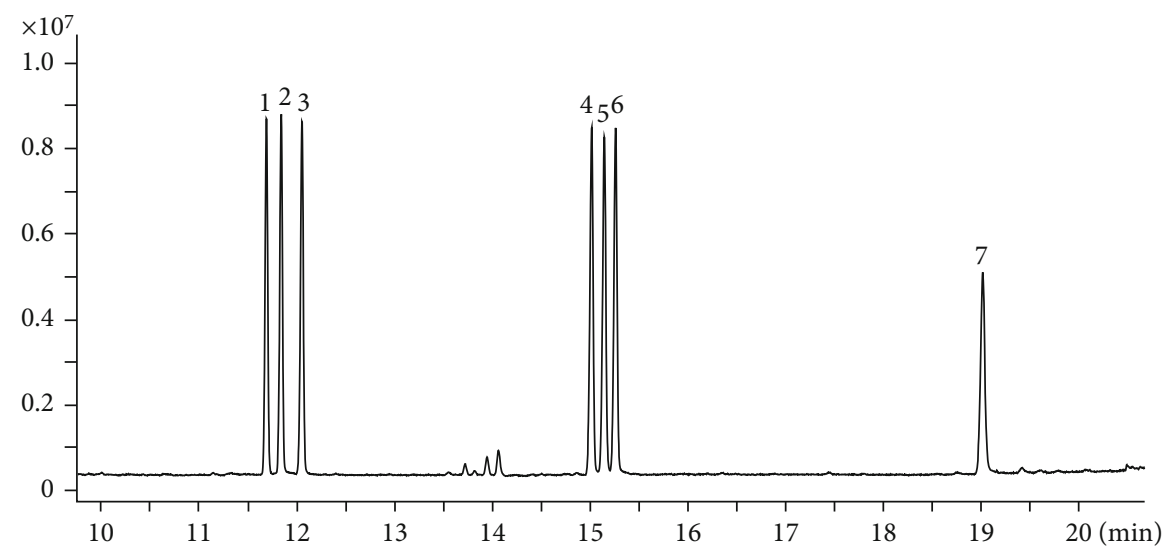

(c)

FIgURE 1: Continued. 


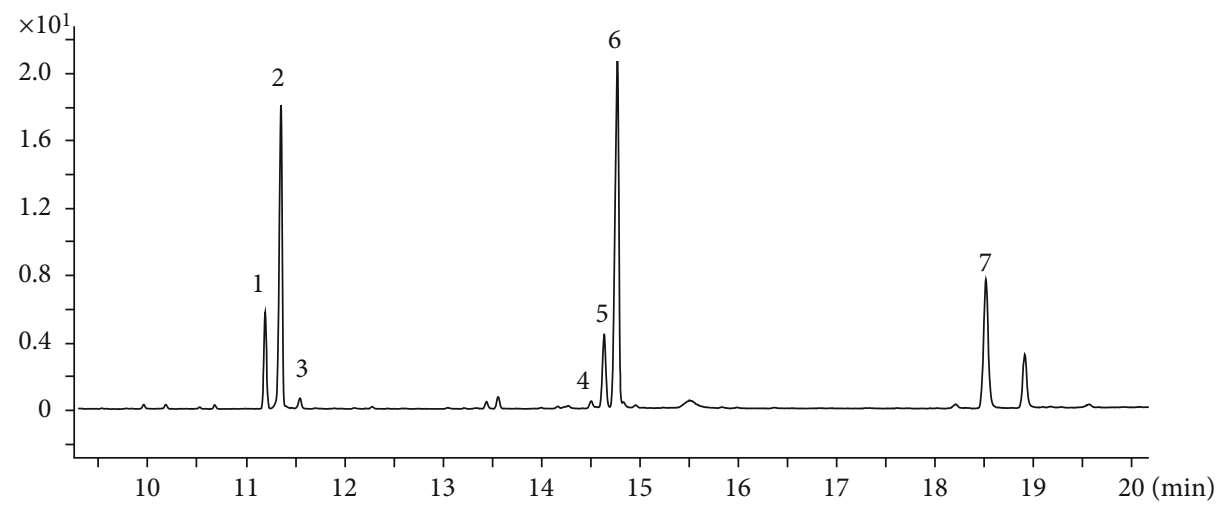

(d)

FIGURE 1: Structural analysis of LFP-a1. (a) FT-IR spectrum; (b) HPGPC profile on OHpak SB-802.5HQ column chromatographic columns; (c, d) GC-MS-based monosaccharide and uronic acid composition of (c) mixed standard and (d) LFP-a1. Peaks: (1) rhamnose, (2) arabinose, (3) xylose, (4) mannose, (5) glucose, (6) galactose, and (7) galacturonic acid.

TABLE 1: FT-IR analysis of functional groups in LFP-a1.

\begin{tabular}{lccc}
\hline Peak $\left(\mathrm{cm}^{-1}\right)$ & Intensity & Characterization & Functional group \\
\hline 3423 & $\mathrm{~S}$ & $-\mathrm{O}-\mathrm{H}$ stretching vibration & $\mathrm{O}-\mathrm{H}$ \\
2933 & $\mathrm{~W}$ & $-\mathrm{C}-\mathrm{H}$ stretching vibration & $-\mathrm{CH}_{2}-$ \\
1628 & $\mathrm{~S}$ & $-\mathrm{C}=\mathrm{O}$ stretching vibration & $-\mathrm{COOH}$ \\
1410 & $\mathrm{M}$ & $-\mathrm{C}-\mathrm{O}$ stretching vibration & $-\mathrm{COOH}$ \\
1074 & $\mathrm{~S}$ & $-\mathrm{C}-\mathrm{O}-\mathrm{C}$ and C-O-H overlaping vibrations & $/$ \\
\hline
\end{tabular}

3.2.3. LFP-a1 Impacted Apoptosis Induction and Cell Cycle Progression in $\mathrm{H}_{2} \mathrm{O}_{2}$-Challenged L02 Cells. Cell apoptosis is a cascade process of programmed cell death viewed as a leading pathway for degenerative disorders [29]. The relation between stress and cell apoptosis has attracted much attention. In addition, cell cycle distribution is of valuable interpretation of changes in cell proliferation and apoptosis [30]. Therefore, induction of apoptosis and cell cycle distribution were detected to reveal whether the apoptotic like mechanism and cell cycle were associated with cytoprotective effect of LFP-a1. Oxidative stress-induced alterations in apoptosis and cell cycle distribution in L02 cell cultures preincubated with LFP-al with $\mathrm{H}_{2} \mathrm{O}_{2}$-triggered oxidative stress are shown in Figure 4.

Figure 4(a) illustrated the variation of nuclear morphology with response to the exogenous LFP-al and $\mathrm{H}_{2} \mathrm{O}_{2}$ insult. To this feature, cells with homogeneously chromatin distribution were considered viable, whereas the presence of chromatin condensation and/or nuclear fragmentation was indicative hallmarks of apoptosis. To confirm and assess the proportion of apoptotic cells, cells were further subjected to Annexin-V/PI staining followed by flow cytometry, in which apoptotic cells were expressed as Annexin $\mathrm{V}$ positive DNA fragmentation (Figure 4(b)). Based on the profound accumulation of chromatin condensation and/or nuclear fragmentation in Hoechst 33342 staining-assisted morphology and Annexin $\mathrm{V}+$ cells in flow cytometric diagram, $\mathrm{H}_{2} \mathrm{O}_{2}$ insult remarkably facilitated apoptosis in L02 cells to $\sim 50 \%$ with respect to the basic level of apoptosis in control group. When preprotected with different concentrations of LFP-a1, however, the abnormal apoptosis progressively decreased to $42.05 \%, 30.75 \%$, and $24.77 \%$, respectively (Figures 4(b) and 4(c)), indicating that in this context, LFPa1 gradually obliterated the occurrence of $\mathrm{H}_{2} \mathrm{O}_{2}$-induced apoptotic death in L02 cells in a dose-dependent manner.

Fidelity of sequential transition from one phase of to another is of great significance to maintain smooth cell cycle progress. Cells must pass through $\mathrm{G}_{0} / \mathrm{G}_{1}, \mathrm{~S}$, and $\mathrm{G}_{2} / \mathrm{M}$ phases sequentially to complete a cycle. Dysfunction of cell cycle regulation is in close connection with, to some extent, the initiation and progression of disorders originated from external injurious factors [31]. In addition to the established role in promoting cell survival and proliferation, ROS can also trigger cell cycle arrest. We thus sought to assess LFP-a1mediated cell cycle progression in $\mathrm{H}_{2} \mathrm{O}_{2}$-challenged cells by analyzing the percentage of cells in the $G_{0} / G_{1}, S$, and $G_{2} / M$ phases (Figures $4(\mathrm{~d})$ and $4(\mathrm{e})$ ). Cells were subjected to PI staining followed by flow cytometric cell cycle analysis for cellular DNA content. Inspection of cell cycle analysis data for L02 cells demonstrated notorious enrichment of $G_{0} / G_{1}$ phase cell populations accompanied by decrement of $S$ phase and $\mathrm{G}_{2} / \mathrm{M}$ phase cell populations in $\mathrm{H}_{2} \mathrm{O}_{2}$ group, indicating DNA damage during $\mathrm{S}$ phase, or unrepaired damage of certain proteins progressing into next phase. When protected with LFP-a1, $G_{0} / G_{1}$ phase population stepwise dropped with the increase of LFP-a1. Commensurately, cells in S phase climbed from $18.0 \%$ to $30.9 \%$. This pattern of cell cycle indicated while $\mathrm{H}_{2} \mathrm{O}_{2}$ challenging meditated cell cycle 


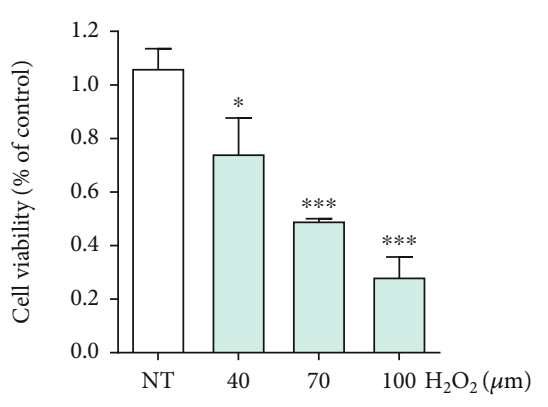

(a)

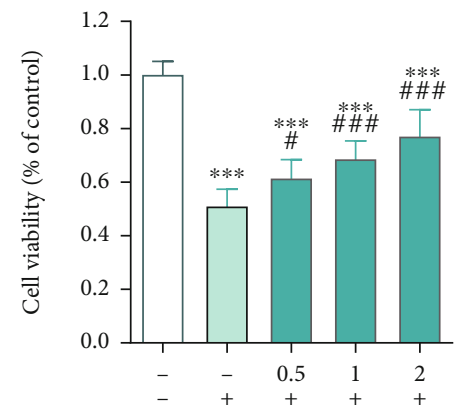

(b)

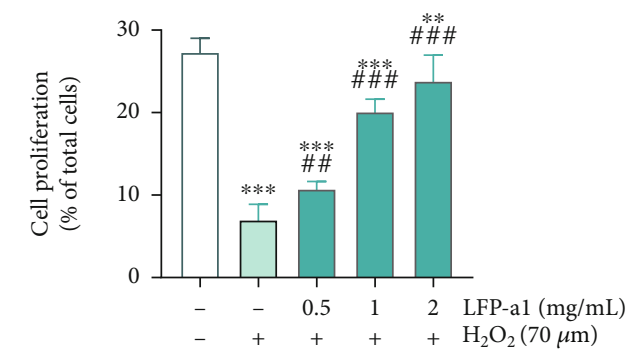

(c)
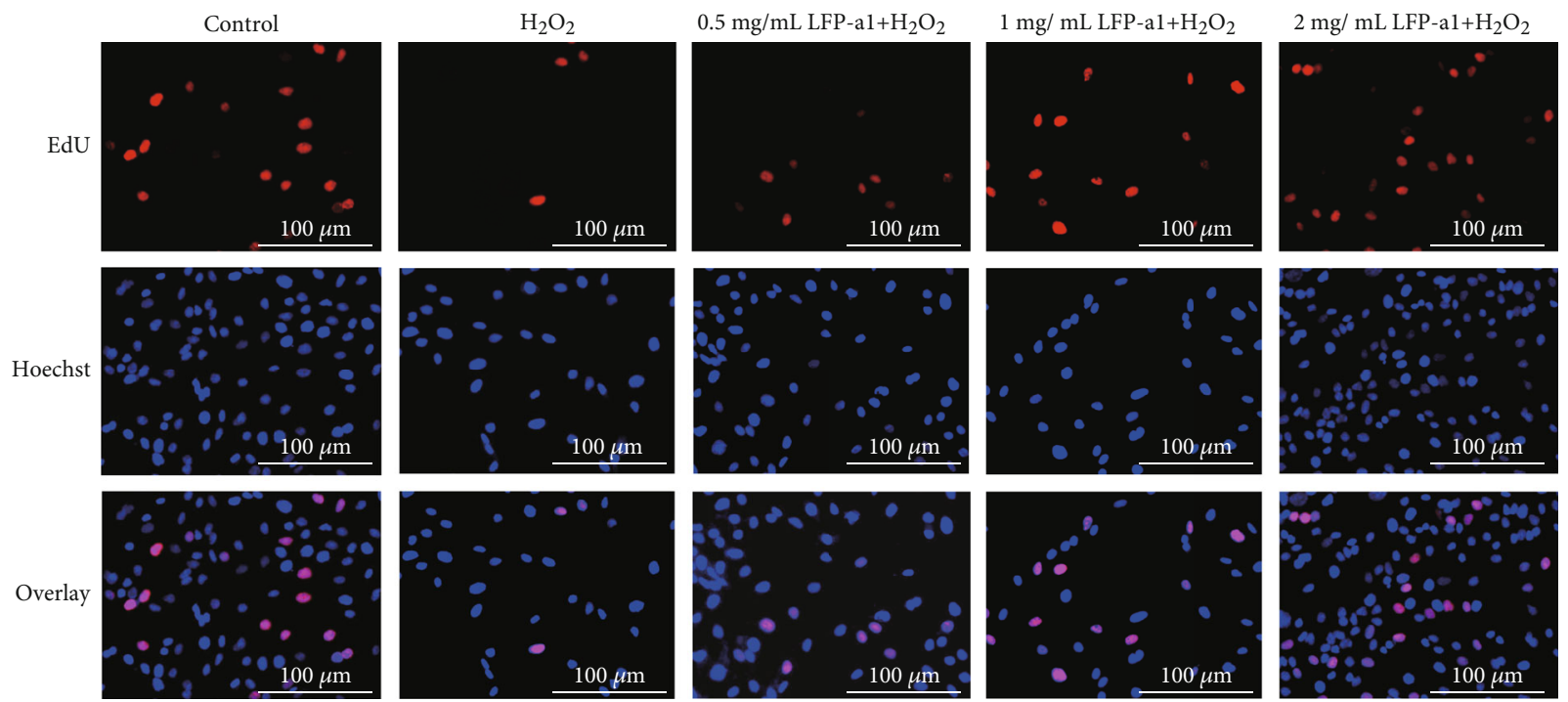

(d)

FIGURE 2: Cytotoxicity of $\mathrm{H}_{2} \mathrm{O}_{2}$ and protective effects of LFP-a1 in $\mathrm{H}_{2} \mathrm{O}_{2}$-challenged L02 cells. (a) Effect of $\mathrm{H}_{2} \mathrm{O}_{2}$ on cell viability of L02 cells, respectively. (b) Effect of LFP-a1 on cell viability of $\mathrm{L} 02$ cells against $\mathrm{H}_{2} \mathrm{O}_{2}$-insult. (c) Effect of LFP-a1 on cell proliferation of L02 cells against $\mathrm{H}_{2} \mathrm{O}_{2}$-insult. (d) Edu and Hoechst 33342 fluorescent staining of L02 cells (EdU: staining in red; Hoechst 33342: staining in blue, original magnification: $\times 200)$. Data are expressed as the mean \pm SD $(n=3)$ and are representative of at least three independent experiments $\left({ }^{*} p<0.05,{ }^{* *} p<0.01,{ }^{* * *} p<0.001\right.$ compared with control cells, ${ }^{\#} p<0.05,{ }^{\# \#} p<0.01$ compared with $\mathrm{H}_{2} \mathrm{O}_{2}$-challenged cells).

progression arrest at $\mathrm{G}_{0} / \mathrm{G}_{1}$ phase to $S$ phase transition, exogenous LFP-a1 was able to accelerate cells passing into $S$ phase from $\mathrm{G}_{0} / \mathrm{G}_{1}$ phase to restart the cell cycle, which further promoted regeneration of $\mathrm{L} 02$ cells in spite of $\mathrm{H}_{2} \mathrm{O}_{2}$ stimuli.

Imbalance between the proapoptotic $\mathrm{Bax}$ and the antiapoptotic Bcl-2 could affect cell death [32]. Therefore, possible modulation in the Bax and Bcl-2 expression upon LFP-al pretreatment was investigated to achieve the visualized blots of apoptosis-related protein expression. As shown in Figure 4(f), the Bax/Bcl-2 expressions underwent a signifi- cant increase/decrease in L02 cells under $\mathrm{H}_{2} \mathrm{O}_{2}$ stimuli. LFP-al pretreatment, however, effectively reversed the imbalance between Bax and Bcl-2 compared with $\mathrm{H}_{2} \mathrm{O}_{2}$ damaged cells. Consistently, the increased expression upon $\mathrm{H}_{2} \mathrm{O}_{2}$ insult of activated caspase- 3 protein, a key downstream effector and the final apoptotic executioner, was significantly blocked by LFP-al pretreatment, albeit no significant variation in full-length pro-caspase-3 expression was observed. The expression of C-Myc, another marker molecule of mitochondrial damage, was curtailed obviously by $\mathrm{H}_{2} \mathrm{O}_{2}$ and 


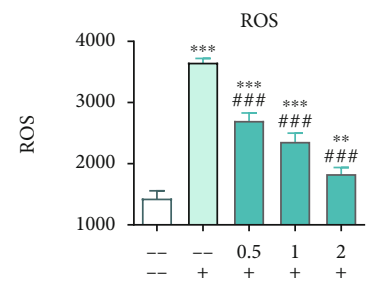

GSH-Px
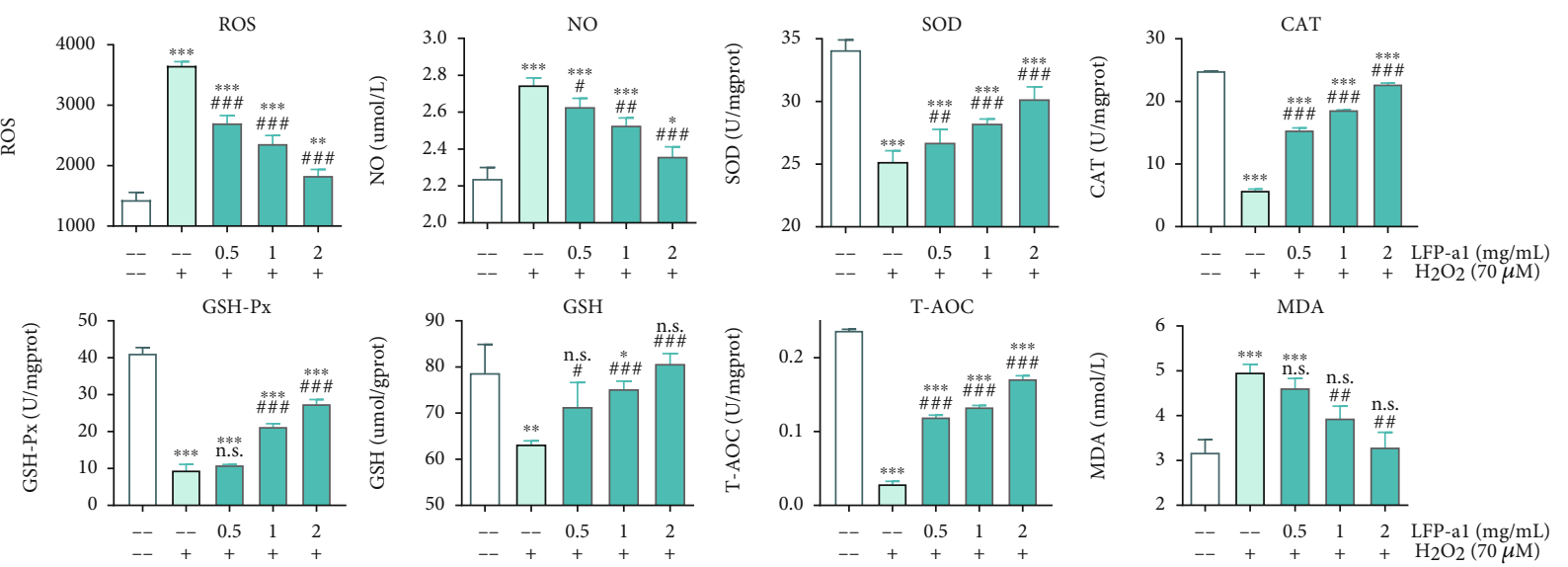

(a)
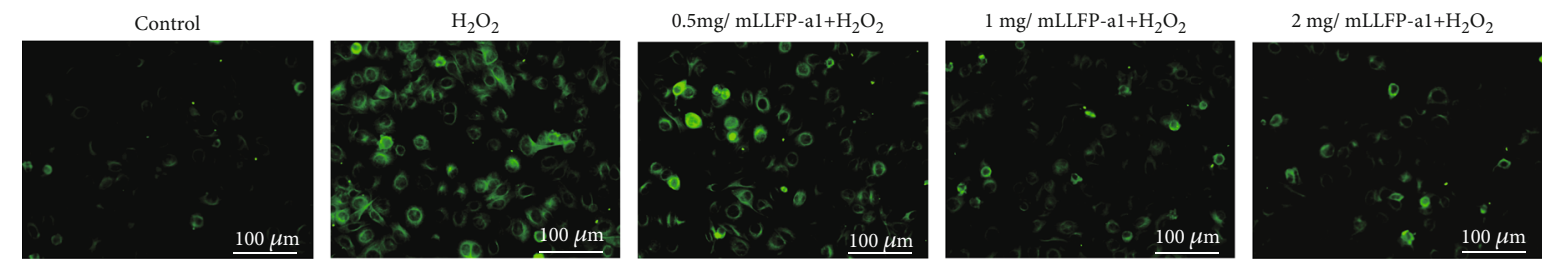

(b)

FIGURE 3: LFP-a1 mitigated $\mathrm{H}_{2} \mathrm{O}_{2}$-induced oxidative stress scenario. (a) Effect of LFP-a1 on ROS production and oxidative stress indicators in $\mathrm{H}_{2} \mathrm{O}_{2}$-challenged L02 cells. (b) ROS detection images of L02 cells. Cells were treated with different concentrations of LFP-a1 and $70 \mu \mathrm{M} \mathrm{H} \mathrm{H}_{2}$ successively. Data were presented as mean $(n=3) \pm \mathrm{SD}$ of three independent experiments $\left({ }^{*} p<0.05,{ }^{* *} p<0.01, * * * p<0.001\right.$ compared with $\mathrm{H}_{2} \mathrm{O}_{2}$ groups, ${ }^{\#} p<0.05,{ }^{\# \#} p<0.01,{ }^{\# \#} p<0.001$ compared with $\mathrm{H}_{2} \mathrm{O}_{2}$-challenged cells).

elevated gradually by LFP-al pretreatment. It can be explained that the hepatoprotective effects of LFP-al against $\mathrm{H}_{2} \mathrm{O}_{2}$-induced toxicity may be attributed, at least in part, to the inhibition of mitochondrial-mediated apoptotic pathway. Elucidating research is still necessary to look further inside the full spectrum of detailed mechanisms underlying.

\subsection{Hepatoprotection of LFP-a1 on TAA-Insulted NAFLD Model Larval Zebrafish In Vivo}

3.3.1. Protective Effect of LFP-a1 on TAA-Induced Hepatic Damage in Larval Zebrafish NAFLD Model. Zebrafish (Danio rerio) has emerged as an advantageous in vivo vertebrate model organism for mechanistic interpreting and highthroughput candidate drug screenings. Zebrafish offers a combination of rapid development, high fecundity, highthroughput screening, and significant morphological and physiological homology to mammals in spite of the reasonable cost $[33,34]$. Specially, zebrafish completes primary liver morphogenesis in $48 \mathrm{~h}$ postfertilization (hpf) and full liver function in $72 \mathrm{hpf}$. The quick liver development and its high conservativeness made zebrafish a universal model organism for hepatotoxicity and hepatoprotection screening, basic understanding of acquired liver diseases [35]. Hereby, to further investigate antioxidant activities of LFP-al and its potential application in NAFLD treatment, larval zebrafish were exposed to exogenous addition of LFP-al in TAAinduced NAFLD model. $3 \mathrm{dpf}$ larvae were pretreated with different concentrations of LFP-al and then damaged by $7 \mathrm{mM}$ TAA. Specially, the transgenic line of zebrafish with enhanced liver fluorescence was used to visualize the liver location and the degree of liver damage. As displayed in Figures 5(a) and 5(b), both liver area and total intensity of larvae were reduced as results of $7 \mathrm{mM}$ TAA insult, indicating significant liver developmental toxicity. Pretreatment with LFP-a1, however, gradually increases the liver area (although not statistically significant) and total fluorescence intensity. In addition, larvae liver gradually regained characteristic morphology with increased concentration of LFP-a1, offering ameliorated phenotypic disorders of liver injuries. Furthermore, transaminase activities of cytosolic liver marker enzymes, ALT and AST, were significantly elevated following TAA exposure. Pretreatment of LFP-a1 significantly prevented TAA-induced hepatotoxicity, as evidenced by the decreased activities of ALT and AST, suggesting that LFP-al attenuated the hepatic dysfunction or degeneration resulted from exogenous TAA application. Similarly, as shown in Figure 5(c), abnormal abundant lipid accumulation characterized with the increased carmine intensity was observed in the larvae after TAA exposure. However, the intensity was gradually decreased upon LFP-al pretreatment, indicating LFP-al reduced the hepatic lipid accumulation on larval zebrafish. These results suggested that LFP-a1 feeding effectively preserved the liver integrity, reversed TAA-caused liver damage, and lipid accumulation in larval zebrafish.

3.3.2. Effect of LFP-a1 against Oxidative Stress in TAADamaged Larval Zebrafish NAFLD Model. Redox homeostasis is pivotal components for maintenance of normal physiological stability. Injury may occur at high level of oxidative 

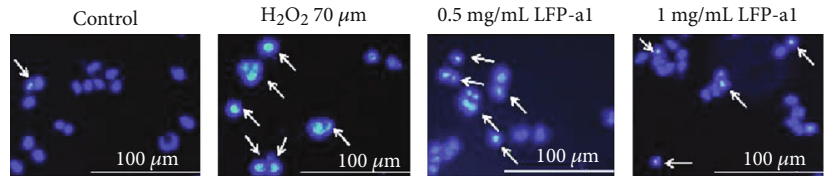

(a)
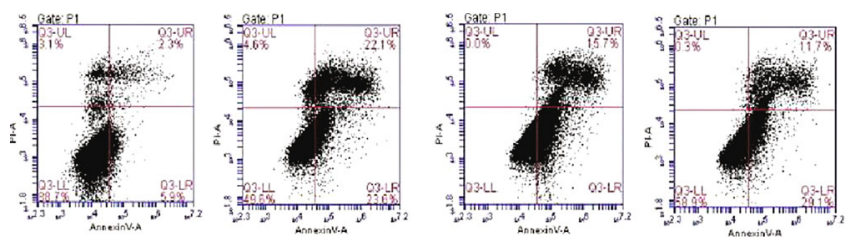

(b)
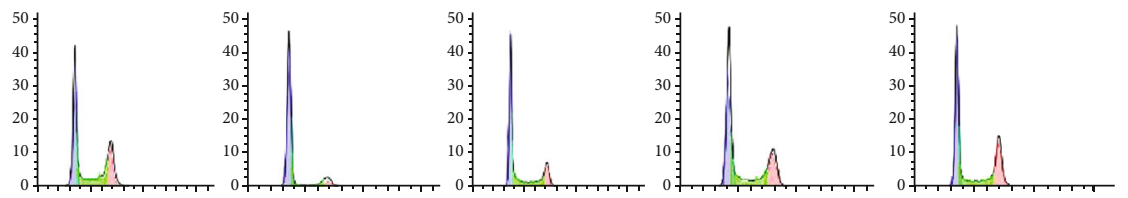

(d)
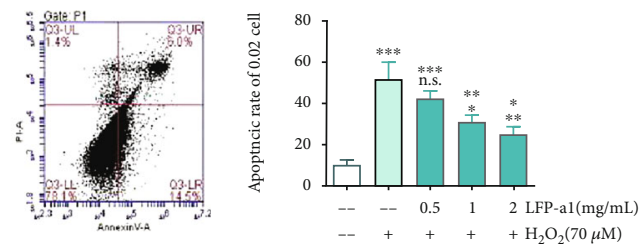

(c)

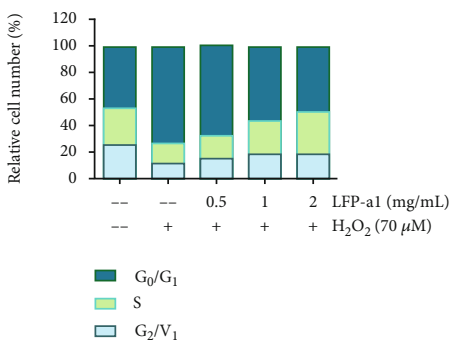

(e)

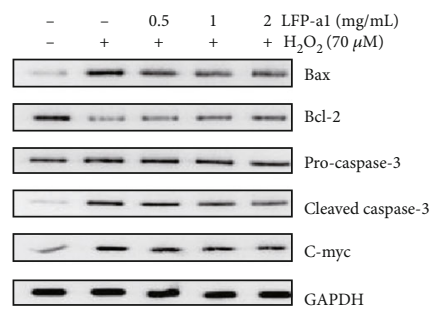

(f)

FIGURE 4: Effects of LFP-a1 on cell apoptosis and cell cycle in $\mathrm{H}_{2} \mathrm{O}_{2}$-challenged L02 cells. Cells were pretreated with different concentrations $(0.5,1.0$, and $2 \mathrm{mg} / \mathrm{mL})$ of LFP-al for $24 \mathrm{~h}$ prior to incubation with $70 \mu \mathrm{M} \mathrm{H}_{2} \mathrm{O}_{2}$ for an extra $24 \mathrm{~h}$. (a) Representative fluorescent images of cells stained with Hoechst 33342 and observed under a fluorescent microscope; (b) flow cytometry analysis of apoptosis after doublestaining with Annexin V-FITC/PI; (c) bar graphs of apoptotic ratio of cells analyzed by flow cytometry; (d) representative DNA histograms of cell cycle distribution after staining with PI; (e) statistical results of population in different cell cycle phases analyzed by flow cytometry; (f) protein expressions of apoptosis-associated biomarkers in L02 cells measured by Western blot. Results were expressed as means $\pm \mathrm{SD}(n=3)$ and representative of at least three separate experiments. ${ }^{*} p<0.05,{ }^{* *} p<0.01,{ }^{* * *} p<0.001$ compared with control cells, ${ }^{\#} p<0.05,{ }^{\# \#} p<0.01,{ }^{\# \# \#} p<0.001$ compared with $\mathrm{H}_{2} \mathrm{O}_{2}$-challenged cells.

stress when systematic adaptation is not adequate for the stockpile of oxidation products. Lipid peroxidation is the downstream consequence of ROS-mediated damage of membrane lipids. To evaluate the protective effect of LFP-a1 against oxidative stress scenario, ROS production and other oxidative stress indices were estimated in TAA-induced larval zebrafish NAFLD model. The biochemical analysis results provided evidence that oxidative stress occurred due to the $3 \mathrm{~d}$ TAA insult as shown by the quantified histograms in Figure 6(a) and representative fluorescence images in Figure 6(b). Compared with the basal level of oxidative stress in physiological status, the imposed TAA initiated deleterious reduction-oxidation disequilibration seen by the increased level of ROS and NO, weakened enzymic defense system (SOD, CAT, and GSH-Px activities), reduced GSH levels and T-AOC, suggesting depletion of antioxidant defense system, and impaired elimination of xenobiotics metabolites. As a result, increased lipid peroxidation was detected in TAA-intoxicated larvae liver. However, the degree of ROS production and disequilibration were obviously ameliorated as a response to the exogenous LFP-a1 feeding. The overproduction of ROS was decreased, accompanying the emergence of the rescued NO concentration and reactivated enzymic defensing. Not unexpectedly, the improved endogenous antioxidative network consequently enhanced the downstream lipid metabolism, as indicated by the decreased level of MDA. These results clearly indicated the effective protection of LFP-al pretreatment against TAA-induced oxidative stress in larval zebrafish NAFLD model.

\subsubsection{Effects of LFP-a1 on Apoptosis-Related Gene Expression} of Zebrafish Larvae with NAFLD. The mRNA expression levels of apoptosis-related factors Bax, Bcl-2, caspase 3, and 

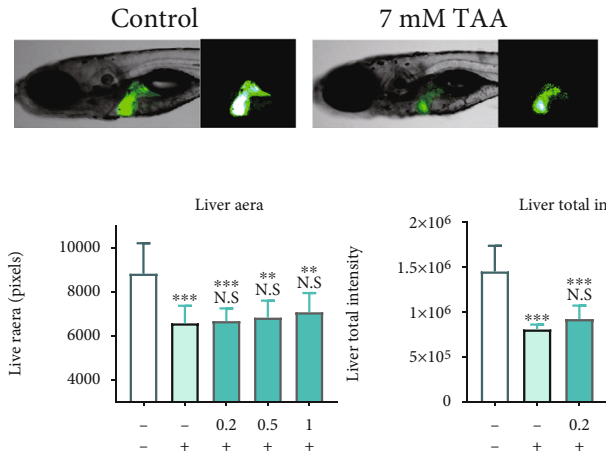

Control
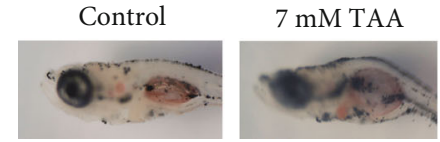

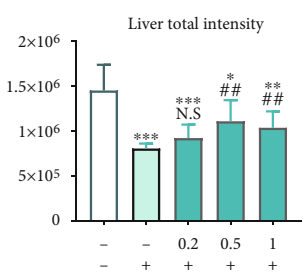

(a)
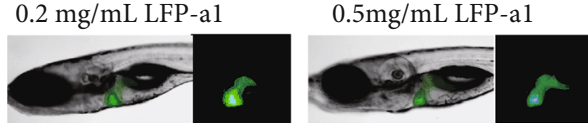

$1.0 \mathrm{mg} / \mathrm{mL}$ LFP-al

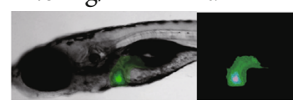

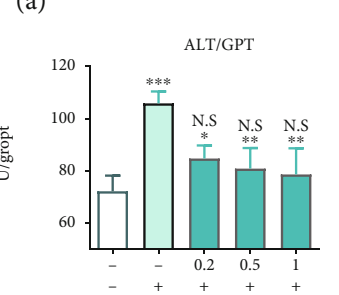

(b)
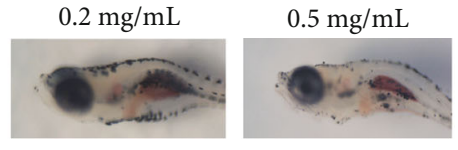

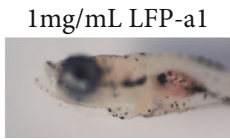

(c)
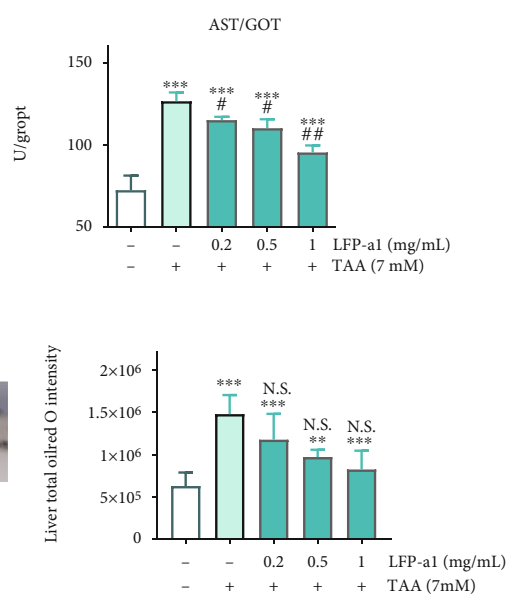

(d)

FIGURE 5: Effects of LFP-al on liver development and function in TAA-damaged zebrafish larvae. (a) Effects of LFP-al on TAA-induced morphological alterations in larvae livers ( $\times 2.5$ magnification); (b) statistical effects of LFP-a1 on TAA-induced zebrafish larvae liver area, fluorescence intensity, and ALT and AST activities; (c) images of LFP-al on lipid accumulation in larvae livers; (d) statistical effects of LFP-al on lipid accumulation in larvae livers $\left({ }^{*} p<0.05,{ }^{* *} p<0.01,{ }^{* * *} p<0.001\right.$ compared with control larvae, ${ }^{\#} p<0.05,{ }^{\# \#} p<0.01$, $\# \#<0.001$ compared with TAA-challenged larvae, N.S.: no significance).
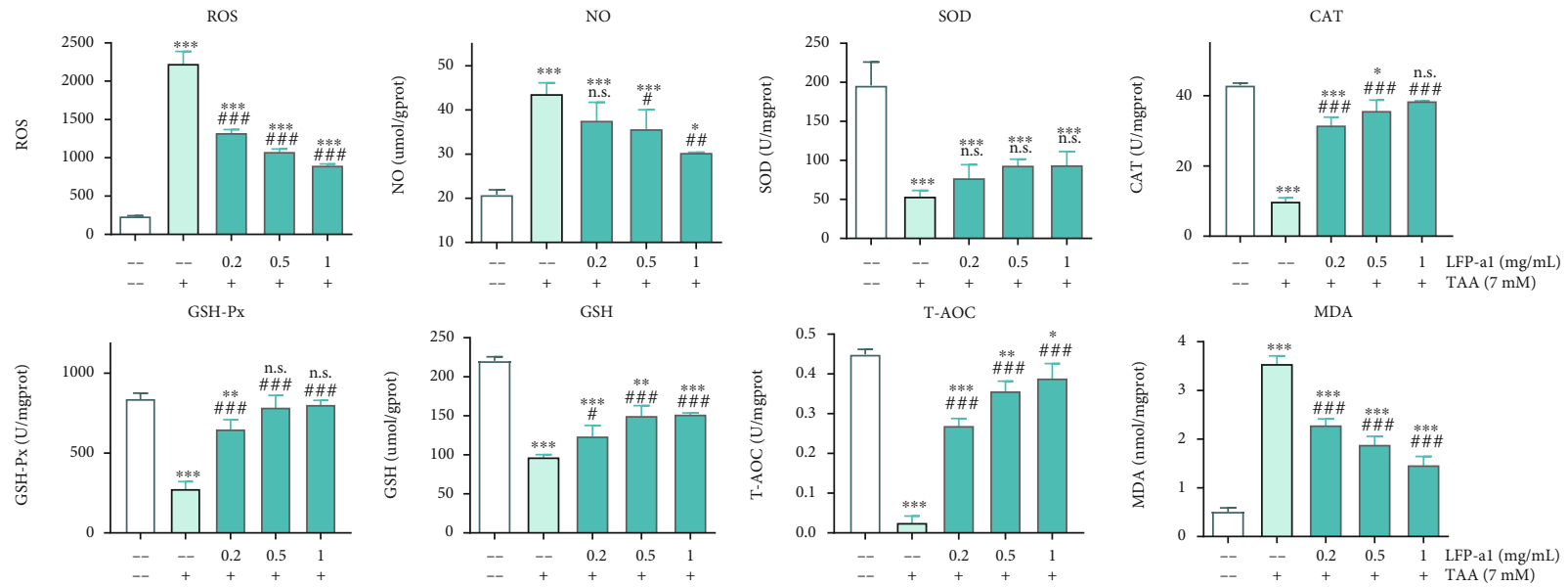

FIGURE 6: LFP-a1 protected zebrafish larvae from TAA-induced oxidative stress (ROS production, NO production, antioxidant enzyme activities of SOD, GSH-Px, and CAT, GSH content, T-AOC, and MDA level). Larvae were treated with different concentrations of LFP-a1 and $7 \mathrm{mM}$ TAA successively. Data were presented as mean $(n=3) \pm \mathrm{SD}$ of three independent experiments $\left({ }^{*} p<0.05,{ }^{* *} p<0.01,{ }^{* * *} p<\right.$ 0.001 compared with control, ${ }^{\#} p<0.05,{ }^{\# \#} p<0.01,{ }^{\# \#} p<0.001$ compared with TAA-challenged larvae, N.S.: no significance).

c-myc were quantitatively analyzed by qPCR amplification to detect DNA damage initiated from etiologic oxidative stress. Consistently with the in vitro assessment, profound ROS accumulation, and depotentiation of ROS scavengers increased oxidative stress, which then initiated apoptotic processes. Luckily, the significant disorganization of $\mathrm{Bax} / \mathrm{Bcl}-2$ ratio initiated by TAA damage was as downmodulated by LFP-a1 as shown in Figure 7. Specially, when care- fully analyzing the overall changing features, this downmodulation was mainly due to an inhibition of Bax expression rather than an increase in Bcl-2 mRNA levels. The changing pattern of mRNA expressions of caspase- 3 and c-myc were observed to be parallel very closely. They both underwent a sharp increase in TAA-challenged larvae, which were restored by LFP-al pretreatment, supporting the importance of LFP-alfor inhibiting apoptosis in NAFLD 

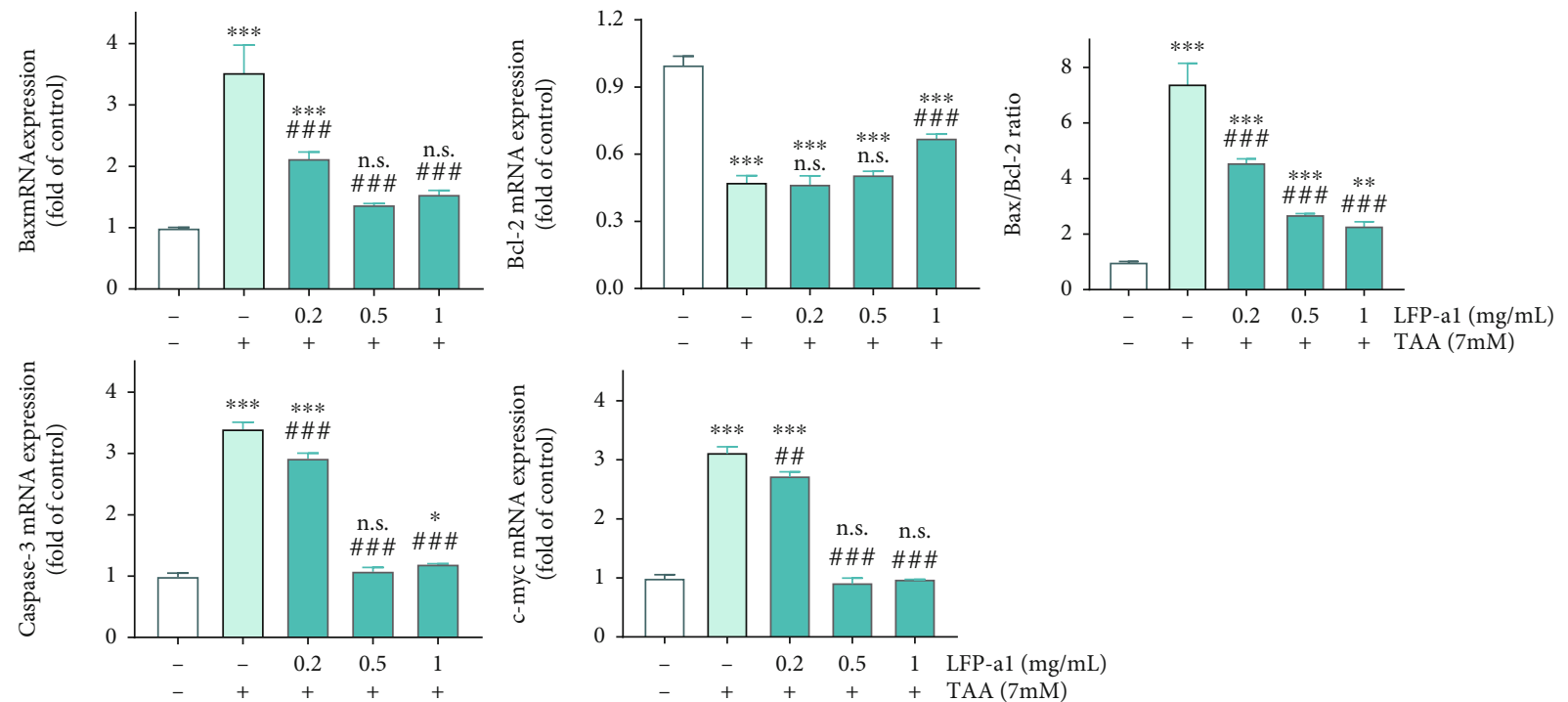

Figure 7: mRNA levels of apoptosis-related gene in larval zebrafish NAFLD model measured by qPCR. Larvae were treated with different concentrations of LFP-a1 and $7 \mathrm{mM}$ TAA successively. Data were presented as mean $(n=3) \pm \mathrm{SD}$ of three independent experiments $\left({ }^{*} p<0.05,{ }^{* *} p<0.01,{ }^{* * *} p<0.001\right.$ compared with control, ${ }^{\#} p<0.05,{ }^{\# \#} p<0.01,{ }^{\# \# \#} p<0.001$ compared with TAA-challenged larvae, N.S.: no significance).

larvae. These results correlated with the alleviated hepatic damage and oxidative stress scenario observed in $\mathrm{H}_{2} \mathrm{O}_{2}$ induced NAFLD model L02 cells in vitro as discussed above.

The targets of hepatic damage triggered by $7 \mathrm{mM}$ TAA were heterogeneously complicated, involving a broad spectrum from the phenotypic and functional changes in the development process, the emergence of disorganization of antioxidant system, and the consequent apoptosis induction, to the metabolic imbalance. Pretreatment of LFP-a1 preserved the liver integrity and showed marked protective effect upon the liver function, terminating the overproduction of ROS that escaped the antioxidant defenses through reorganization of the antioxidant system. LFP-al feeding alleviated TAA-caused DNA damage through downregulation of abnormal apoptosis, further suggesting the hepatoprotective effect and potential application of LFP-al in the prevention and treatment of NAFLD.

\section{Conclusions}

In the present study, an acidic heteropolysaccharide fraction, LFP-a1, was purified from Lycii fructus. The preliminary structure of LFP-al was characterized. Together with the results from in vitro and in vivo analyses, the extent of oxidative stress determines, at least in part, the cell fate leading to the activation of mitochondrial-mediated apoptotic pathways in both $\mathrm{H}_{2} \mathrm{O}_{2}$-induced NAFLD model of L02 cells and TAA-induced NAFLD model of zebrafish larvae. Exogenous LFP-a1 successfully protected against oxidative stress-triggered apoptosis, indicating that inhibition of abnormal apoptosis may encode the underlying mechanism contributing to the cytoprotective effect of LFP-a1 during oxidative stress. Clearly, to confirm the protective effect and potential therapeutic significance of LFP-1, there is a need for longer term trails with increased number of larvae. The systematic evaluation of the cluster of oxidative stress-associated, apoptosis-associated, and lipid metabolism-associated biomarkers is further needed to elucidate the incompletely understood molecular mechanisms. Despite the interpretative constraints, our findings underscore the potential of LFP-a1 in preventing or treatment of NAFLD or other oxidative stress-related diseases, which has important implications when proceeding to the next stages of therapeutic approaches.

\section{Data Availability}

Data in this study are available from the corresponding author upon request.

\section{Conflicts of Interest}

The authors declare that the research was conducted under no commercial or financial relationships that could be construed as a potential conflict of interest.

\section{Authors' Contributions}

F.Z and X.Z contributed equally to this work. J-A.D, F.Z, and X.Z are responsible for the conceptualization; F.Z, X.Z, YT.G, M.W, S.G, X-F.Z, Z-H.Z, J-Z.L, B-W.Q, Y-C.Y, L.Y, CM.L, and C-L.X for the data curation; F.Z, X.Z, S.G, F-N.C, and C-M.L for the formal analysis; J-A.D and D-W.Q for the supervision; F.Z, X.Z, S.G, and F-N.C for the writing-original draft preparation; and F.Z, X.Z, S.G, F-N.C, C-M.L, C-L.X, D-W.Q, and J-A.D for the writing-review and editing. 


\section{Acknowledgments}

This study was financially supported by the National Natural Science Foundation of China under grant nos. 81773837 (F.Z), 81960711 (X.Z), and 81703396 (S.G) and Key Project of Jiangsu Collaborative Innovation Center of Chinese Medicinal Resources Industrialization under grant no. 012092002001-2 and ZDXM-2-11 (F.Z).

\section{Supplementary Materials}

Table S1: nucleotide sequences of the primers used to quantify mRNA levels by qPCR. (Supplementary Materials)

\section{References}

[1] J. Willebrords, I. V. A. Pereira, M. Maes et al., "Strategies, models and biomarkers in experimental non-alcoholic fatty liver disease research," Progress in Lipid Research, vol. 59, pp. 106-125, 2015.

[2] C. Zhu, Y. Dong, H. Liu, H. Ren, and Z. Cui, "Hesperetin protects against $\mathrm{H} 2 \mathrm{O}$ 2-triggered oxidative damage via upregulation of the Keap1-Nrf2/HO-1 signal pathway in ARPE-19 cells," Biomedicine \& Pharmacotherapy, vol. 88, pp. 124-133, 2017.

[3] M. Karlsson, C. Frennesson, T. Gustafsson, U. T. Brunk, S. E. G. Nilsson, and T. Kurz, "Autophagy of iron-binding proteins may contribute to the oxidative stress resistance of ARPE-19 cells," Experimental Eye Research, vol. 116, pp. 359-365, 2013.

[4] L. Zhang, Q. Zhao, L. Wang, M. Zhao, and B. Zhao, "Protective effect of polysaccharide from maca (Lepidium meyenii ) on Hep-G2 cells and alcoholic liver oxidative injury in mice," International Journal of Biological Macromolecules, vol. 99, pp. 63-70, 2017.

[5] R. D. Cummings and J. M. Pierce, "Preface," in Handbook of Glycomics, vol. 1, no. 9, pp. xi-xiii, Academic Press, 2010.

[6] Y. Niu, J. Dong, H. Jiang et al., "Effects of polysaccharide from Malus halliana Koehne flowers in cyclophosphamide-induced immunosuppression and oxidative stress on mice," Oxidative Medicine and Cellular Longevity, vol. 2020, Article ID 1603735, 10 pages, 2020.

[7] Y. G. Xia, T. L. Wang, S. M. Yu, J. Liang, and H. X. Kuang, "Structural characteristics and hepatoprotective potential of Aralia elata root bark polysaccharides and their effects on SCFAs produced by intestinal flora metabolism," Carbohydrate Polymers, vol. 207, pp. 256-265, 2019.

[8] X. An, Q. Bao, S. di et al., "The interaction between the gut microbiota and herbal medicines," Biomedicine \& Pharmacotherapy, vol. 118, article 109252, 2019.

[9] R. Jia, Z. Li, J. Wu, Z. Ou, Q. Zhu, and B. Sun, "Physicochemical properties of polysaccharide fractions from Sargassum fusiforme and their hypoglycemic and hypolipidemic activities in type 2 diabetic rats," International Journal of Biological Macromolecules, vol. 147, pp. 428-438, 2020.

[10] Y.-W. Zhao, L. Liu, C.-Y. Li, H. Zhang, X.-Y. Sun, and J.M. Ouyang, "Preprotection of tea polysaccharides with different molecular weights can reduce the adhesion between renal epithelial cells and nano-calcium oxalate crystals," Oxidative Medicine and Cellular Longevity, vol. 2020, Article ID 1817635,13 pages, 2020 .
[11] Y. Li, D. D. Lin, B. Jiao et al., "Purification , antioxidant and hepatoprotective activities of polysaccharide from Cissus pteroclada Hayata," International Journal of Biological Macromolecules, vol. 77, pp. 307-313, 2015.

[12] X. He, J. Fang, Y. Ruan, X. Wang, Y. Sun, and N. Wu, "Structures, bioactivities and future prospective of polysaccharides from Morus alba (white mulberry): a review," Food Chemistry, vol. 245, pp. 899-910, 2018.

[13] F. A. Pettolino, C. Walsh, G. B. Fincher, and A. Bacic, "Determining the polysaccharide composition of plant cell walls," Nature Protocols, vol. 7, no. 9, pp. 1590-1607, 2012.

[14] Z. Zhang, Y. Zhou, H. Fan et al., "Effects of Lycium barbarum polysaccharides on health and aging of C. elegans depend on daf-12/daf-16," Oxidative Medicine and Cellular Longevity, vol. 2019, 6379414 pages, 2019.

[15] Y. Lu, S. Guo, F. Zhang et al., "Comparison of functional components and antioxidant activity of lycium barbarum L. Fruits from different regions in China," Molecules, vol. 24, no. 12, p. 2228, 2019.

[16] M. Jin, Q. Huang, K. Zhao, and P. Shang, "Biological activities and potential health benefit effects of polysaccharides isolated from Lycium barbarum L.," International Journal of Biological Macromolecules, vol. 54, pp. 16-23, 2013.

[17] M. Dubois, K. A. Gilles, J. K. Hamilton, P. A. Rebers, and F. Smith, "Colorimetric method for determination of sugars and related substances," Analytical Biochemistry, vol. 28, no. 3, pp. 350-356, 1956.

[18] M. M. Bradford, "A rapid and sensitive method for the quantitation of microgram quantities of protein utilizing the principle of protein-dye binding," Analytical Biochemistry, vol. 72, no. 1-2, pp. 248-254, 1976.

[19] K. Ogawa, T. Wanatabe, J. Tsurugi, and S. Ono, "Conformational behavior of a gel-forming $(1 \rightarrow 3)-\beta$-D-glucan in alkaline solution," Carbohydrate Research, vol. 23, no. 3, pp. 399-405, 1972.

[20] J. Lehrfeld, "Simultaneous gas-liquid chromatographic determination of aldoses and alduronic acids," Journal of Chromatography. A, vol. 408, pp. 245-253, 1987.

[21] C.-T. Chang, M. Korivi, H. C. Huang et al., "Inhibition of ROS production, autophagy or apoptosis signaling reversed the anticancer properties of Antrodia salmonea in triple-negative breast cancer (MDA-MB-231) cells," Food and Chemical Toxicology, vol. 103, pp. 1-17, 2017.

[22] M. Jodeiri Farshbaf, M. Forouzanfar, K. Ghaedi et al., "Nurr1 and PPAR $\gamma$ protect $\mathrm{PC} 12$ cells against MPP+ toxicity: involvement of selective genes, anti-inflammatory, ROS generation, and antimitochondrial impairment," Molecular and Cellular Biochemistry, vol. 420, no. 1-2, pp. 29-42, 2016.

[23] H. M. Kir, M. O. Dillioglugil, M. Tugay, C. Eraldemir, and H. K. Özdoğan, "Effects of vitamins E, A and D on MDA, GSH, NO levels and SOD activities in 5/6 nephrectomized rats," American Journal of Nephrology, vol. 25, no. 5, pp. 441-446, 2005.

[24] S. Bahramzadeh, M. Tabarsa, S. G. You, K. Yelithao, V. Klochkov, and R. Ilfat, "An arabinogalactan isolated from _Boswellia carterii_: Purification, structural elucidation and macrophage stimulation via $\mathrm{NF}-\kappa \mathrm{B}$ and MAPK pathways," Journal of Functional Foods, vol. 52, pp. 450458, 2019.

[25] A. Sila, Z. Kamoun, Z. Ghlissi et al., "Ability of natural astaxanthin from shrimp by-products to attenuate liver oxidative 
stress in diabetic rats," Pharmacol. Reports, vol. 67, no. 2, pp. 310-316, 2015.

[26] S. Saggu, M. I. Sakeran, N. Zidan, E. Tousson, A. Mohan, and H. Rehman, "Ameliorating effect of chicory (Chichorium intybus L.) fruit extract against 4-tert-octylphenol induced liver injury and oxidative stress in male rats," Food and Chemical Toxicology, vol. 72, pp. 138-146, 2014.

[27] V. P. Ničković, T. Novaković, S. Lazarević et al., "Pre- vs. posttreatment with melatonin in $\mathrm{CCl} 4$-induced liver damage: oxidative stress inferred from biochemical and pathohistological studies," Life Sciences, vol. 202, pp. 28-34, 2018.

[28] J. Ma, M. Li, P. K. Kalavagunta et al., "Protective effects of cichoric acid on $\mathrm{H} 2 \mathrm{O} 2$-induced oxidative injury in hepatocytes and larval zebrafish models," Biomedicine \& Pharmacotherapy, vol. 104, no. 639, pp. 679-685, 2018.

[29] M. Kara, E. Ozcagli, and B. Alpertunga, "Effects of stanozolol on apoptosis mechanisms and oxidative stress in rat cardiac tissue," Steroids, vol. 134, pp. 96-100, 2018.

[30] B. Du, Y. Fu, X. Wang et al., "Isolation, purification, structural analysis and biological activities of water-soluble polysaccharide from Glehniae radix," International Journal of Biological Macromolecules, vol. 128, pp. 724-731, 2019.

[31] W. Zhang, S. Lv, J. Liu et al., "PCI-24781 down-regulates EZH2 expression and then promotes glioma apoptosis by suppressing the PIK3K / Akt / mTOR pathway," Genetics and Molecular Biology, vol. 724, pp. 716-724, 2014.

[32] V. Manickam, M. Periyasamy, V. Dhakshinamoorthy, L. Panneerselvam, and E. Perumal, "Recurrent exposure to ferric oxide nanoparticles alters myocardial oxidative stress, apoptosis and necrotic markers in male mice," Chemico-Biological Interactions, vol. 278, pp. 54-64, 2017.

[33] K. Jia, B. Cheng, L. Huang et al., "Thiophanate-methyl induces severe hepatotoxicity in zebrafish," Chemosphere, vol. 248, p. 125941, 2020.

[34] X. Wang, M. Shen, J. Zhou, and Y. Jin, "Chlorpyrifos disturbs hepatic metabolism associated with oxidative stress and gut microbiota dysbiosis in adult zebrafish," Comparative Biochemistry and Physiology Part C: Toxicology \& Pharmacology, vol. 216, pp. 19-28, 2019.

[35] J. Zhang, Y. Deng, B. Cheng et al., "Protective effects and molecular mechanisms of baicalein on thioacetamideinduced toxicity in zebrafish larvae," Chemosphere, vol. 256, p. $127038,2020$. 